students. Last year they met for their 3rd BPU-SB Conference in Bansko. The BPU Balkan Physics Student Training Programme has been started in Italy, with funding is provided via an agreement between the ICTP and the Union.

As a result of these initiatives, Balkan physicists obtained much information about each other's scientific activities. One also notes that these initiatives motivated them to make independent visits to each other's universities and national research centres, and to participate in other activities in the region beside the BPU's through private and national sponsorship. Under BPU coordination, Balkan-wide physics research institutes and research groups started to form. Several Balkan projects with collaboration involving these institutions and groups are now coordinated by the Union (see table). Involving about 70 Balkan physicists, they are supported by national institutions and research centres. The ICTP and CERN provide laboratories, computers, and library facilities under special agreements; living and travel expenses are covered by Balkan funding from several sources.

The BPU also started to publish a quarterly scientific journal in 1993 entitled Balkan Physics Letters (BPL). Partly devoted to the publications of Balkan cooperation projects and the presentations at the BPU conferences and schools, it aims to integrate publications published by universities and national laboratories.

In its short history, the Balkan Physical Union has been able to stimulate an effective collaboration between Balkan scientists through the joint publication of scientific papers and the preparation of theses. It is significant that one can find among these works the first article, realized within a Balkan co-project, by Greek and Turkish physicists (from Thessaloniki and Istanbul). Within such projects, Balkan physicists have started to supervise the theses of students from other Balkan countries, and many publications have resulted from this type of collaboration.

Many will probably appreciate that Balkan scientists need more help in order to preserve their scientific and cultural traditions and to promote lasting Balkanwide collaboration so as to ensure peace in the region. Finally, on behalf of all Balkan physicists, I would like to thank CERN, ICTP, the many sponsoring international and national organizations, societies, foundations, and especially friends throughout the Balkans for their contributions to the Union's efforts and activities.

\section{An International Centre Founded}

Seven scientific and medical institutions in Yugoslavia (Serbia and Montenegro) and one from Bulgaria founded in Belgrade on 17 July 1996 the TESLA Scientific Centre (TSC), a regional centre for fundamental and applied research in physics, chemistry, biology, materials science, nuclear medicine, and radiology based at Belgrade's VINČA Institute of Nuclear Sciences. The Centre is organized as an association of institutions from southeastern Europe interested in using and developing its principal facility, the TESLA Accelerator Installation. Another task is to provide additional training opportunities for talented young scientists, engineers and disciplines within the selected fields.

The installation is an ion-accelerator complex consisting of three machines, and

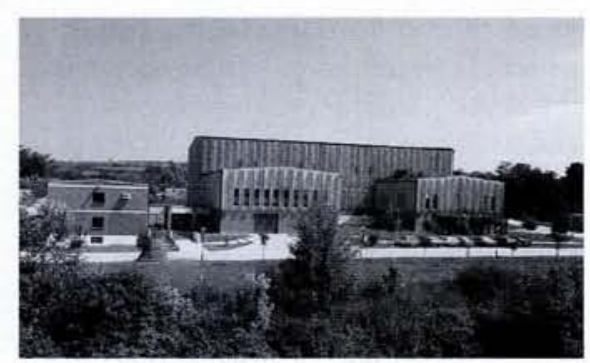
physicists in a number of new and modern a number of low-and high-energy experimental channels (see figure). The building was completed in May 1992 and construction of the accelerator started shortly after. The TESLA Advisory Committee responsible for overseeing the construction is chaired by G. Plass (CERN) and the TESLA Programme Committee is chaired by Yu. Organessian (JINR, Dubna). The first experiments with the ion beams are planned for 1997. Meanwhile, user programmes are being prepared (see insert).

\section{TESLA Experimental Programmes}

- Excitation of ions by electrons.

- Modification and analysis of the physical properties of materials by ion beams.

- Radiation physics with light and heavy ions.

- Physics of thin crystals.

- Nuclear reactions with heavy ions at low and intermediate energies.

- Radiolysis in condensed systems induced by light and heavy ions.

- Three-dimensional distribution of radiation defects induced by light and heavy ions.

- Biological effects induced by irradiation with light and heavy ions.

- Production of radioisotopes and radiopharmaceuticals.

For information: Dr. N. Nešković, TESLA Scientific Centre, POB 522, 11001 Belgrade. Tel.: +381-11-45 49 65; fax: +381-11-44622 26; http://vincy.bg.ac.yu/

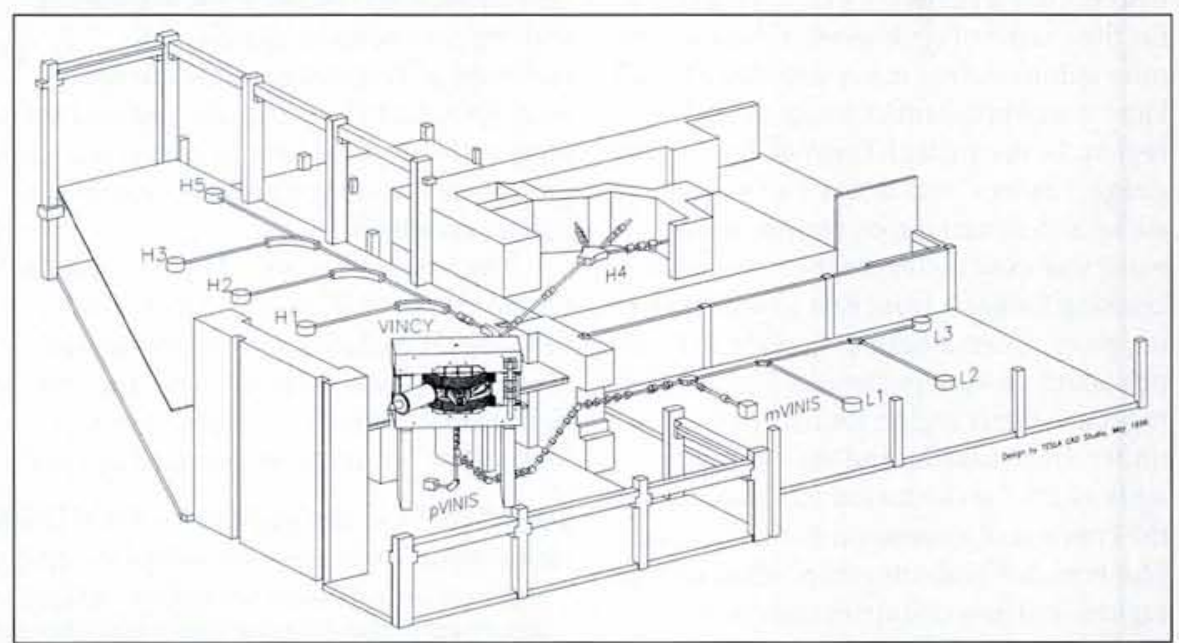

A photograph (upper) of the VINČA Institute of Nuclear Sciences, Belgrade., and a schematic drawing (lower) of VINČA's TESLA accelerator facility. The facility comprises a compact isochronous cyclotron, the VINCY Cyclotron, an electron cyclotron resonance heavy-ion source, the mVINIS Ion Source, and a volume light-ion source, the pVINIS Ion Source. The low-energy experimental channels from mVINIS are indicated as L1-3 and the high-energy channels from VINCY as $\mathrm{H} 1-\mathrm{H} 5$. VINCY will deliver, for example, $\mathrm{N}$, Ar and Xe ions as well as protons ( $2 \mu \mathrm{A}$ at $66 \mathrm{MeV} ; 60 \mu \mathrm{A}$ at $11-16 \mathrm{MeV})$, and deuterons $(20 \mu \mathrm{A}$ at $43-73 \mathrm{MeV})$. The first beam to be extracted will comprise $30 \mathrm{MeV}$ protons at $40 \mu \mathrm{A}$ obtained using a $\mathrm{H}^{2+}$ ion beam extracted from pVINIS; it will initially be used in early-1998 to produce radioisotopes. In delivering, for example, $40 \mu \mathrm{A}$ of $150 \mathrm{keV} \mathrm{N}^{6+}$ ions and $40 \mu \mathrm{A}$ of $500 \mathrm{keV} \mathrm{Xe}^{20+}$ ions, the mVINIS source will be able to produce ions of gaseous and solid substances as well as heavy ions of lower energies above $10 \mathrm{keV}$. The first ion beam extracted from mVINIS will be a $40 \mu \mathrm{A}$ beam beam of $\mathrm{Xe}^{20+}$ ions at $200 \mathrm{keV}$; it will initially be used in September 1997 for modifiying of materials. Finally, the pVINIS source will be able to deliver $H, D ; H^{2+}, H^{3+}$, $D^{2+}$, and $D^{3+}$ light ions. 